\title{
Modal Sosial Dalam Pemberdayaan Perempuan Pada Sektor Informal Di Kelurahan Karangrejo, Kecamatan Karangrejo, Kabupaten Magetan
}

\author{
Harianto \\ Fakultas Ilmu Sosial Dan Ilmu Politik, Universitas Merdeka Madiun, Jl. Serayu No.79, Madiun, 63133 \\ E-mail: harianto@unmer-madiun.ac.id
}

\begin{abstract}
Social capital consists of three main pillars, namely trust, norms and networks. Everything will be examined through a description of the informal sector seen from women who work as traders in Karangrejo Village, Karangrejo District, Magetan Regency. The research problem that will be answered in this study is knowing social capital in empowering women in the informal sector. The purpose of this study was to determine the description of social capital in empowering women traders in Karangrejo Village. Researchers used a descriptive qualitative approach with questionnaire data collection methods and documentation. The participation of women in the informal sector in Kelurahan Karngrejo turns out to provide many functions for women's self-development. At first they have not been able to identify the potential that exists in them, now they can recognize their own potential so that women can apply it through the skills they have mastered. Social capital efforts in women's empowerment are expected to motivate women to be more advanced, independent and be able to develop their potential. In society so that they can be more empowered and improve their social welfare as well as help the family economy.
\end{abstract}

Keywords-: social capital; women empowerment and the informal sector.

\section{PENDAHULUAN}

Modal merupakan hal yang penting dalam kehidupan bermasyarakat terutama dalam upaya pembangunan yang berkelanjutan. Ketersediaan modal merupakan jawaban dari pernyataan tentang mengapa suatu kelompok masyarakat suatu daerah lebih maju daripada daerah lainnya dalam bidang pembangunan. Salah satu modal yang sangat diperlukan adalah modal sosial. (Masik A, 2005:4). Modal social didefinisikan sebagai serangkaian nilai-nilai atau norma- norma informal yang dimiliki bersama di antara para anggota suatu kelompok yang memungkinkan terjalinnya kerjasama di antara mereka."Dari sudut pandang sosiologi, elemen utama dalam modal social mencakup norms, reciprocity, trust, dan network". (Masik A, 2005:15) Partisipasi masyarakat dalam jaringan, resiprositas, kepercayaan normasosial, sifat keumuman pemilikan, dan sikap warga yang proaktif sangat dibutuhkan oleh modal sosial agar dapat beroperasi dengan baik terutama dalam kegiatan pembangunan desa. Tingkat partisipasi masyarakat dapat mempengaruhi dan dipengaruhi oleh berbagai hal salah satunya adalah modal sosial. Pengelolaan dengan mengedepankan partisipasi dipercayaakan menumbuhkan rasa memiliki (sense ofbelonging).

Modal sosial dewasa ini menjadi hal yang sangat dibutuhkan dalam menentukan keberhasilan pembangunan maupun pemberdayaan, tidak terkecuali dalam pemberdayaan perempuan pada sektor informal. Dalam perkembangannya keadaan masyarakat mengalami perubahan, trustmengalami pergeseran, kecurigaan, kebencian, ketidakpercayaan sertarasa individualis menjadi atmosfer dalam masyarakat.Untuk itu, modal social penting dikembangkan untuk menumbuhkan partisipasi serta kerjasama dalam masyarakat itu sendiri. Penguatan modal social dirasa penting dilakukandalam upaya meningkatkan kerjasama diantara masyarakat. Modal social dapat menjadi suatu perekat yang mampu mengikat masyarakat secara bersama-sama. Dengan mempererat modal sosial yang dimiliki oleh masyarakat seperti rasa percaya (trust), jaringan (network), serta nilai-nilai dan norma yang telah ada, diharapkan perempuan dapat lebih mampu meningkatkan kerjasama, kebersamaan, rasa tolongmenolong dan kegotongroyongan diantara mereka sehingga kegiatan yang dilakukan dapat berjalan lebih efektif dan kesejahteraan social juga lebih mudahtercapai.

Proses pemberdayaan perempuan di Kelurahan Karangrejo menyangkut budaya yang terdapat di dalamnya nilai-nilai yang berkembang di masyarakat, seperti nilai ekonomi yakni mendapatkan penghasilan, nilai politik yakni ikut serta dalam pengambilan keputusan baik di dalam keluarga maupun masyarakat dan nilai social yakni membantu sesame anggota masyarakat untuk mencapai tujuan bersama. Nilai social tersebut merupakan aspek modal sosial yang mempengaruhi prosespemberdayaan.

Sebagaimana yang diungkapkan Fukuyama (2005:17) bahwa "Kenyataan bahwa nilai-nilai moral dan aturan sosial bukanlah semata-mata kekangan sewenang- wenang atas pilihan individu: sebaliknya, itulah prasyarat bagi setiap jenis kerja sama".

Para perempuan harus menciptakan, membangun serta menggali potensi- potensi yang ada di dalam diri mereka. Pada penelitian ini potensi perempuan yang akan digali adalah keterampilan perempuan diKelurahan Karangrejo dalam berdagang. Di balik kegiatan berdagang apakah terdapat cerminan modal sosial yang berpengaruh pada pemberdayaan perempuan di sektor informal. 
Keikutsertaan para perempuan di sektor informal yang berada di Kelurahan Karangrejo ternyata memberikan banyak fungsi bagi pengembangan diri perempuan. Mereka semulanya belum dapat mengidentifikasi potensi yang ada di dalam dirinya kini dapat mengenalipotensi diri mereka masing-masing sehingga para perempuan dapat mengaplikasikannya melalui keterampilan yang mereka kuasai.

Kegiatan pemberdayaan perempuan juga mempengaruhi secara psikologi khususnya dalam hal membangun kepercayaan diri perempuan terhadap dirinya maupun dihadapan orang lain. Pemberdayaan perempuan juga sebagai proses pendidikan bagi perempuan untuk mentransformasikan dirinya baik secara ide maupun praktis. Upaya pemberdayaan perempuan diharapkan dapat memotivasi perempuan untuk lebih maju, mandiri serta dapat mengembangkan potensinya dimasyarakat sehingga mereka dapat lebih berdaya serta meningkatkan kesejahteraan sosialnya sekaligus dapat membantu perekonomiankeluarga.

Konsep teori modal sosial yang digunakan oleh Coleman dalam Sihombing berasal dari tindakan individu sebagai hasil interaksinya dan kemudian mendatangkan manfaat bagi publik. "Sebagai atribut dari struktur sosial dimana seseorang terlibat di dalamnya, kapital sosial /sosial bukanlah kepemilikan pribadi yang bermanfaat hanya bagi orang-orang yang memilikinya."

Manfaat bagi publik/kebersamaan merupakan salah penting yang menjadi nilai utama modal sosial. Dengan manfaat bersama yang ada di dalam konsep modal sosial satu aspek lain, perihal modal sosial dengan modal fisik maupun modal manusia (human capital). (Zulkifly A. Humami, 2006:18).

Selanjutnya, Coleman dalam tulisan Zulkifly Al Humami (2006:23), mengidentifikasikan konsep modal sosial ke dalam tiga hal, "kewajiban dan harapan yang bersandar pada kepercayaan atau kesetiaan (trustworthiness) dalam lingkungan sosial; saluran informasi yang bersumber dari kapabilitas struktur sosial; dan norma-norma yang disertai sanksi-sanksi efektif."

Beragamnya modal sosial di Kelurahan Karangrejo yang dapatmeningkatkan pemberdayaan perempuan pada sektor informal tentu saja sangat menarik untuk di kaji lebih lanjut. Modal sosial atau kontribusi para perempuan di sektor informaliniakan menentukan apakah terdapat hubungan modal sosial dengan pemberdayaan perempuan, dapat didasarkan pada formasi modal sosial dengan pemberdayaan perempuan dan kondisi riil di KelurahanKarangrejo.Berdasarkan latar belakang diatas, peneliti tertarik untuk melakukan penelitian mengenai "Modal Sosial Dalam Pemberdayaan Perempuan Pada Sektor Informal Di Kelurahan Karangrejo, Kecamatan Karangrejo, Kabupaten Magetan “.

Berdasarkan latar belakang masalah diatas dapat dirumuskan masalah penelitian ini adalah : Bagaimanakah modal sosial dalam pemberdayaan perempuan pada sektor informal di Kelurahan Karangrejo, Kecamatan Karangrejo, Kabupaten Magetan ?

Berdasarkan rumusan masalah diatas, maka tujuan penelitian ini adalah untuk mendeskripsikan modal sosial dalam pemberdayaan perempuan pada sektor informal di Kelurahan Karangrejo, Kecamatan Karangrejo, Kabupaten Magetan.

\section{METODE PENELITIAN}

\section{A. Jenis Penelitian}

Penelitian ini menggunakan deskriptif dengan pendekatan penelitian kualitatif. Penelitian ini dipilih karena untuk menyajikan data secara sistematis, faktual dan akurat mengenai fakta-fakta yang ada dilapangan.

\section{B. Variabel dan Indikator Penelitian}

Dalam penelitian ini variabelnya tunggal, yaitu modal social dalampemberdayaan masyarakat pada sector informal dengan indicator :

1. Kepercayaan (Trust)

2. Norma (Norms)

3. Jaringan (Networking)

\section{Populasi penelitian}

Populasi dalampenelitian ini adalah perempuan yang bekerja disektor informal diKelurahan Karangrejo, Kecamatan Karangrejo, Kabupaten Magetanyang telahdi identifikasi ada sebanyak 35orang.

\section{Sumber Data}

\section{DataPrimer}

Data primer adalah data-data yang diperoleh secara langsung diperoleh dari penelitian. Sumadi Suryabrata (1993:93) berpendapat bahwa dataprimer yaitu "data yang langsung dikumpulkan oleh peneliti dari sumber pertamanya."Adapun data primer yang diperlukan dalam penelitian ini adalah data-data yang diperoleh dari pemberian questioner.

\section{DataSekunder}

Data sekunder adalah data yang diperoleh secara tidak langsung dan tersedia ditempat penelitian biasanya berupa dokumen-dokumen. Sumadi Suryabrata (1993:94) berpendapat bahwa disamping data primer terdapat data sekunder yang sering juga diperoleh dari peneliti."Data sekunder itu biasanya telah tersusun dalam bentuk dokumen-dokumen."

Berdasarkan penjelasan di atas, dapat disimpulkan bahwa sumber penelitian dapat diperoleh secara langsung melalui responden dan secara tidak langsung melalui dokumen yang telah ada. 
Website : http://sosial.unmermadiun.ac.id/index.php/sosial

\section{E. Teknik pengumpulan data}

Adapun teknik pengumpulan data yang dilakukan dalam penelitian ini terdiri dari 2 macam yaitu kuesioner dan dokumentasi.

\section{F. Teknik Analisis Data}

Dalam penelitianini, peneliti menggunakan statistic deskriptifseperti yang dijelaskan oleh Sugiyono, "Statistik Deskriptif adalahstatistik yang digunakan untuk menganalisis data dengan caramendeskripsikan atau menggambarkan data yang telah terkumpulsebagaimana adanya tanpa bermaksud membuat kesimpulan yangberlaku umum atau generalisasi”. Sedangkan untuk keperluan analisis data, peneliti menggunakan skala Likert sebagaimana dikutip Sugiyono (2004:169) yaitu“ skala Likertdigunakan untuk mengukur sikap, pendapat dan persepsi se-seorangatau sekelompok orang tentang fenomena sosial.”

\section{III.HASIL PENELITIAN DAN PEMBAHASAN}

Interpretasi data hasil penelitian disajikan berdasarkan indikator variabel modal social dalam pemberdayaan perempuan pada sectorinformal.

\section{A. Rekapitulasi IndikatorKepercayaan}

Tabel 1. Klasifikasi Nilai Indikator Kepercayaan

\begin{tabular}{|l|c|c|}
\hline \multicolumn{1}{|c|}{ Klasifikasi } & Frekuensi & Prosentase \\
\hline a. Sangat baik & 6 & $17.14 \%$ \\
\hline b.Baik & 11 & $31.43 \%$ \\
\hline c. Cukup baik & 7 & $20.00 \%$ \\
\hline d. Kurang baik & 9 & $25.71 \%$ \\
\hline e. Tidak baik & 2 & $5.71 \%$ \\
\hline Jumlah & 35 & $100.00 \%$ \\
\hline Sumber : Daftar Primer Yang Diolah
\end{tabular}

Berdasarkan tabel diatas menunjukkan, bahwa 17,14\% relatif sangat baik, 31,45\% relatif baik, $20 \%$ relatif cukup baik, $25,71 \%$ relatif kurang baik, 5,71\% relatif tidak baik. Dengan demikian dapat diintrepetasikan sebagian besar responden menilai kepercayaan di Kelurahan Karangrejo adalah relatif baik, yaitu sebesar 31,43\%.

\section{B. Rekapitulasi Indikator Norma}

Berikut disajikan data rekapitulasi indikator norma sebagai pada tabel di bawah ini.

Tabel 2. Klasifikasi Nilai Indikator Norma

\begin{tabular}{|l|c|r|}
\hline \multicolumn{1}{|c|}{ Klasifikasi } & Frekuensi & Prosentase \\
\hline a. Sangat baik & 2 & $5.71 \%$ \\
\hline b. Baik & 12 & $34.29 \%$ \\
\hline c. Cukup baik & 11 & $31.43 \%$ \\
\hline d. Kurang baik & 9 & $25.71 \%$ \\
\hline e. Tidak baik & 1 & $2.86 \%$ \\
\hline Jumlah & 35 & $100.00 \%$ \\
\hline Sumber : Daftar Primer Yang Diolah
\end{tabular}

Sumber : Daftar Primer Yang Diolah

Berdasarkan tabel diatas menunjukkan, bahwa 5,71\% relatif sangat baik, 34,29\% relatif baik, 31,43\% relatif cukup baik, $25,71 \%$ relatif kurang baik, 2,86\% relatif tidak baik. Dengan demikian dapat diintrepetasikan sebagian besar responden menilai norma di Kelurahan Karangrejo adalah relatif baik, yaitu sebesar 34,29\%. 
Website : http://sosial.unmermadiun.ac.id/index.php/sosial

\section{Rekapitulasi Indikator Jaringan}

Berikut disajikan data rekapitulasi inidikator jaringan sebagaimana pada tabel berikut ini.

Tabel 3. Klasifikasi Nilai Indikator Jaringan

\begin{tabular}{|l|c|c|}
\hline \multicolumn{1}{|c|}{ Klasifikasi } & Frekuensi & Prosentase \\
\hline a. Sangat baik & 1 & $2.86 \%$ \\
\hline b.Baik & 6 & $17.14 \%$ \\
\hline c. Cukup baik & 15 & $42.86 \%$ \\
\hline d. Kurang baik & 7 & $20.00 \%$ \\
\hline e. Tidak baik & 6 & $17.14 \%$ \\
\hline Jumlah & 35 & $100.00 \%$ \\
\hline
\end{tabular}

Sumber : Daftar Primer Yang Diolah

Berdasarkan tabel diatas menunjukkan, bahwa 2,86\% relatif sangat baik, 17,14\% relatif baik, 42,86\% relatif cukup baik, $20 \%$ relatif kurang baik, $17,14 \%$ relatif tidak baik. Dengan demikian dapat diintrepetasikan sebagian besar responden menilai jaringan di Kelurahan Karangrejo adalah cukup baik, yaitu sebesar42,86\%.

Selanjutnya, setelah disajikan rekapitulasi indikator, berikut disajikan rekapitulasi data variabel modal Sosial dalam pemberdayaan perempuan pada sektor informal.

Tabel 4. Rekapitulasi Variabel Modal Sosial

\begin{tabular}{|l|c|c|}
\hline \multicolumn{1}{|c|}{ Klasifikasi } & Frekuensi & Prosentase \\
\hline a. Sangat baik & 4 & $11.43 \%$ \\
\hline b. Baik & 6 & $17.14 \%$ \\
\hline c. Cukup baik & 9 & $25.71 \%$ \\
\hline d. Kurang baik & 8 & $22.86 \%$ \\
\hline e. Tidak baik & 8 & $22.86 \%$ \\
\hline Jumlah & 35 & $100.00 \%$ \\
\hline
\end{tabular}

Berdasarkan tabel di atas menunjukkan, bahwa $11,43 \%$ relatif sangat baik, $17,16 \%$ relatif baik, $25,71 \%$ relatif cukup baik, $22,86 \%$ relatif kurang baik, 22,86\% relatif tidak baik. Dengan demikian keadaan lapangan menunjukan bahwa modal sosial di Kelurahan Karangrejo adalah cukup baik yaitu sebesar $25,71 \%$.

\section{IV.KESIMPULAN}

Berdasarkan hasil penelitian data yang telah dianalisa dan diinterprestasikan diatas, Modal Sosial Dalam Pemberdayaan Perempuan Pada Sektor Infomal, maka penulis memberikan beberapa kesimpulan yaitu :

1. Dari hasil penelitian Variabel Bebas "Modal Sosial" pada pedagang di Kelurahan Karangrejo adalah relatif cukup baik dengan responden menjawab pertanyaan cenderung pada pilihan ganda huruf c yang bermakna cukup baik, memiliki presentasi tertinggi, yaitu sebesar 25,71\%.

2. Dari hasil penelitian Variabel Terikat "Pemberdayaan Perempuan" pada pedagang Keleurahan Karangrejo adalah relatif cukup baik, dengan responden menjawab pertanyaan cenderung pada pilihan ganda huruf c yang bermakna cukup baik, memiliki presentase tertinggi, yaitu sebesar $25,71 \%$.

3. Bahwa prosentase tertinggi variabel bebas (modal sosial) berada pada kategori nilai cukup baik yaitu sebesar $25,71 \%$, sedangkan prosentase tertinggi variabel terikat (permberdayaan perempuan) berada pada kategori nilai cukup baik yaitu sebesar 25,71\%. Dengan demikian dapat diinterpretasikan bahwa modal sosial di sektor informal Kelurahan Karangrejo Kecamatan karangrejo Kabupaten Magetan cukup berdampak bagi pemberdayaan perempuan.

Berdasarkan penelitian yang telah dilaksanakan, maka dapat direkomendasikan beberapa saran yang mungkin dapat digunakan sebagai bahan pertimbangan untuk menentukan langkah selanjutnya, yaitu :

1. Bagi pedagang di Kelurahan Karangrejo untuk terus meningkatkan jaringan hubungan relasi, kerjasama, interaksi dan hubungan saling percaya antar pedagang maupun dengan pemerintah desa. Dikarenakan data yang didapat dari tabel 41 hasil penelitian menunjukan dari 35 responden, bahwa 1 responden atau 2,86\% memberikan jawaban sangat baik, 6 responden atau $17,14 \%$ memberikan jawaban baik, 15 responden atau 42,86\% memberikan jawaban cukup baik, 7 responden atau $20 \%$ memberikan jawaban kurang baik, 6 responden atau 17,14\% memberikan jawaban tidak baik. Dari hasil tersebut maka tingkat hubungan relasi, kerjasama, interaksi dan hubungan saling percaya antar pedagang maupun dengan pemerintah desa masih kurang baik, maka dapat disimpulkan bahwa Modal Sosial memberi peluang untuk meningkatkan jaringan hubungan relasi, kerjasama, interaksi dan hubungan saling percaya antar pedagang maupun dengan pemerintah desa, sehingga perlu lebih dikembangkan lagi Modal Sosial agar dapat memberikan kerjasama yang baik antarpedagang. 
2. Bagi pedagang di Kelurahan Karangrejo untuk meningkatkan partisipasi dan respon dalam sosialisasi yang diberikan oleh pemerintah dalam upaya pemberdayaan perempuan pada sektor informal agar pemerintah dalam meningkatkan kualitas pemberdayaan perempuan berjalan sesuai dengan harapan pemerintah dan memberikan banyak fungsi bagi pengembangan diri perempuan. Dikarenakan data yang didapat dari tabel 47 hasil penelitian menunjukan dari 35 responden, bahwa 3 responden atau 8,57\% memberikan jawaban sangat baik, 5 responden atau 14,29\% memberikan jawaban baik, 11 responden atau 31,42\% memberikan jawaban cukup baik, 13 responden atau 37,17\% memberikan jawaban kurang baik, 3 responden atau 8,57\% memberikan jawaban tidak baik. Dari hasil tersebut maka tingkat partisipasi pedagang masih kurang baik, maka dapat disimpulkan bahwa Modal Sosial memberi peluang untuk meningkatkan partisipasi pedagang dalam upayapemberdayaanperempuan diharapkan dapat memotivasi perempuan untuk lebih maju, mandiri serta dapat mengembangkan potensinya dimasyarakat sehingga mereka dapat lebih berdaya serta meningkatkan kesejahteraan sosialnya sekaligus dapat membantu perekonomiankeluarga

3. Bagi pemerintah desa supaya lebih efektif dalam mengontrol harga dagangan di Kelurahan Karangrejo dengan menyidak setiap bulannya secara rutin agar harga dagangan tetap stabil dan tidak adanya pelonjakan harga yang siknikfikan yang menimbulkan pro dan kontra antar pedagang, karena dalam penelitian ini pada tabel 49 menghasilkan prosentase pemerintah desa dalam melakukan kontrol terhadap pedagang yaitu dari 35 responden, bahwa 2 responden atau 5,71\% memberikan jawaban sangat baik dalam melakukan kontrol, 8 responden atau 22,89\% memberikan jawaban baik dalam melakukan kontrol, 3 responden atau 8,57\% memberikan jawaban cukup baik dalam melakukan kontrol, 12 responden atau 34,29\% memberikan jawaban kurang baik dalam melakukan kontrol, dan 10 responden atau 28,57\% memberikan jawaban tidak baik dalam melakukan kontrol. Dari hasil tersebut maka tingkat dalam melakukan kontrol terhadap pedagang masih kurang baik. Maka perlu adanya peningkatan dalam melakukan kontrol terhadap pedagang agar tidak menimbulkan pro dan kontra antarpedagang.

4. Bagi pedagang di Kelurahan Karangrejo untuk lebih pintar dalam memanfaatkan dan menggunakan fasilitas yang disediakan pemerintah dalam menunjungan pedagang dalam berdagang di pasar. Karena dalam penelitian ini pada tabel 51 menghasilkan prosentase yaitu dari 35 responden, bahwa 1 responden atau 2,86\% memberikan jawaban sangat baik, 4 responden atau $11,43 \%$ memberikan jawaban baik, 9 responden atau 25,71\% memberikan jawaban cukup baik, 13 responden atau 37,14\% memberikan jawaban kurang baik, dan 8 responden atau 22,86\% memberikan jawaban tidak. Dari hasil tersebut maka tingkat pedagang memanfaatkan fasilitas masih kurangbaik.Maka perlu adanya kesadaran pedagang dalam memanfaatkan dan menggunakan fasilitas yang sudah disediakan, agar fasilitas yang disediakan Pemerintah Desa tidak terbengkalai dan tidak dibangun secara sia-sia.

\section{UCAPAN TERIMAKASIH}

Penelitian ini dapat dilaksanakan dengan lancar berkat bantuan dari beberapa pihak.Pada kesempatan ini ucapan terima kasih disampaikan kepada Kepala Kelurahan Karangrejo Kecamatan Karangrejo Kabupaten Magetan yang telah membantu pelaksanaan penelitian. Ucapan terima kasih disampaikan juga kepada Rektor dan Jajaran Lembaga Penelitian dan Pengabdian Masyarakat Universitas Merdeka Madiun yang telah membantu dalam penelitian serta pemberi dana penelitian.

\section{VI.DAFTAR PUSTAKA}

Adik Wibowo, 1997, Memampukan Wanita Agar Menggunakan Hak Reproduksi,dalam Smita Noto dan harian Kompas Agus Ahmad Syafi'I, Manajemen Masyarakat Islam

Cahyono, 2012, Peran Modal Sosial Dalam Peningkatan, Jakarta : Metro Dalam Coleman, J. 1999, Social Capital in the Creation of Human Capital Cambridge:Harvard University Press.

Concept, Metodology andScope, di dalam Sethuraman, S.V. (ed.) (1981a),The Urban Informal Sector in Developing Countries: Employment, Poverty and Environment,ILO,Geneva.

Edi Suharto, 2005, Membangun Masyarakat Memberdayakan Rakyat, Bandung: Refika Aditama

Edi Suharto, Membangun Masyarakat Memberdayakan Rakyat

Francis Fukuyama, 2005, Guncangan Besar: Kodrat Manusia dan Tata Sosial Baru, Jakarta:PT.Gramedia

Fukuyama,1995,Trust :The Social Virtues and the Creation of Prosperity, New York : The Free Press.

GunawanSumohadiningrat,PembangunanDaerahdanPengembangan Masyarakat

Handoyo, Peranan Modal Sosial dalam Meningkatkan Kesejahteraan, Semarang : Radar Semarang

Harsono, 2014, Jurnal Kebijakan dan Administrasi Publik.

Harsono, 2014, Peranan Modal Sosial dalam Pembangunan, Semarang: Politeknik NegeriSemarang.

Hidayat, SoewarnoUrip,.1979, Pengembangan Sektor Informal Dalam Pembangunan Nasional: Masalahdan Prospek. PPESM, Bandung : Fakulas Ekonomi Pajajaran

Isbandi Rukminto Adi, 2002, Pemikiran-pemikiran dalam pembangunan "kesejahteraan sosial, Jakarta: LP FEUI.

Jim Ife, 2005, Community Development, Australia: Longman

Kebijakan Pembangunan Pemberdayaan Perempuan, Jakarta: KMNPP, BKKBN,UNFPA, 2003

Keith, "Small-Scale Entrepeneur in Ghanaand Development Planning, di dalamThe Journalof Development Studies, Vol.6, No.4, 1970

Laura Evelyn R. Sihombing, Kehidupan Sebuah Kampung Tua Jakarta: Studi Tentang Modal Sosial dalam Rangka Pemberdayaan Komunitas Kampung Luar Batang - Jakarta Utara, Depok: FISIP UI

Masik A, 2005, Hubungan Modal sosial dan Perencanaan, Yogyakarta : Pustaka Pelajar

Masik, 2015, Hubungan Modal Sosial dan Perencanaan, Jurnal Perencanaan Wilayah dan Kota, Vol.16/No.3, Desember 2015

Masri Singarimbun \& Sofian Effendi, 1987, Metodologi Penelitian Sosial,Jakarta: Penerbit LP3ES

Mely G. Tan, 1997, Perempuan dan Pemberdayaan: Makna Fakta, Dalam Smita Noto Susanto dan E.Kristi Poerwandari, Perempuan dan Pemberdayaan, Jakarta: Obor dan Harian Kompas 
Website : http://sosial.unmermadiun.ac.id/index.php/sosial

Nasdian FT. 2014. Pengembangan Masyarakat. Jakarta (ID) : Yayasan Pustaka Obor Indonesia

Nasdian, 2006, Modal Sosial Konsep dan Aplikasi, Jakarta: LIPI Jakarta

Petunjuk Pelaksanaan Pemberdayaan Wanita Nelayan Oleh Departemen Kelautan dan Perikanan Bagian Proyek Pemberdayaan Sosial Ekonomi Ma yarakat Pesisir, 2001

Riant Nugroho, 2008, Gender dan Administrasi Publik, Yogyakarta: Pustaka Pelajar

Srihartini, 2003, Pondok Pesantren dan Pemberdayaan Ekonomi Masyarakat, Jurnal PMI

Sugiono, 2004, Metode Penelitian Administrasi, Bandung: Alfabeta

Suharsimi Arikunto, 1992, Prosedur Penelitian Suatu Pendekatan, Jakarta: Penerbit Raneka Cipta.

Sukmadinata,2007,MetodePenelitian pendidikan,Bandung:Remaja Rosdakarya.

Sumadi Suryabrata,1983, Metodologi Penelitian, Raja Grafindo, Jakarta

Sutrisno Hadi, 1999,Statistika Jilid I, Yogyakarta:Fakultas Psikologi UGM

Syahyuti, 2008, Peran Modal Sosial, Jakarta : Elizabeth

Zulkifli Al-Humami, 2006, Kapital Sosial Pedagang Kaki Lima (PKL): Studi tentang Sosiabilitas Kumintas Pedagang Angkringan di Kota Yogyakarta, Depok: Fisip UI. 